\title{
Childhood unintentional burn prevention: knowledge and practices among caretakers in a semi-urban community in Sri Lanka
}

\author{
Dilshan Wijeratne $^{1 *}$, Ranjith Batuwanthudawe ${ }^{2}$ \\ ${ }^{1}$ Postgraduate Institute of Medicine, University of Colombo, Sri Lanka; ${ }^{2}$ Health Education Bureau, Ministry of \\ Health, Sri Lanka \\ ${ }^{*}$ Correspondence: dilshanain3@gmail.com
}

DOI: http://doi.org/10.4038/jccpsl.v23i1.8089

Received on: 30 October 2016

Accepted on: 24 January 2017

\begin{abstract}
Background: Accidental burns are a common cause of morbidity and mortality among children under five years. Knowledge and practices of the principal caretakers are directly associated with child's safety.

Objective: To describe the knowledge and practices on childhood unintentional burn prevention among the principal caretakers of children under five years in a semi-urban community in Sri Lanka.

Methods: A community-based cross-sectional study was conducted. The computed sample size was 506. A two-stage cluster sampling technique was used to select the study population of principal caretakers of children below five years in Chilaw MOH area. Their knowledge and practices related to unintentional burn prevention were measured using a pre-tested, interviewer-administered questionnaire. Multiple linear regression analysis was used to identify the socio-demographic factors associated with caretakers' knowledge and practices.

Results: In $90.5 \%$ of the households, mother was the principal caretaker. The median age of principal caretakers was 27 years ( $\mathrm{lQR}=24-31$ years). The mean scores obtained for knowledge and practices were 75.8\% $(\mathrm{SD}=11.2 \%)$ and $67.6 \%(\mathrm{SD}=12.8 \%)$, respectively. These scores revealed a moderate positive correlation $(\mathrm{r}=0.59, \mathrm{p}<0.001)$. Three-quarter of caretakers were aware that children are more vulnerable for burns while $63.1 \%$ believed that accidental burns are preventable. Over $70 \%$ of the caretakers knew that many injuries can be avoided by keeping children away from the kitchen, but only 39.2\% houses had safety barriers to stop children entering the kitchen. Two-third of the caretakers ensured that their children were constantly under close supervision. Significantly better knowledge scores were seen when mother was the principal caretaker $(p=0.002)$, with higher education level of the caretaker $(\mathrm{p}<0.001)$ and with higher family income $(\mathrm{p}=0.04)$. Significantly better safe practices were demonstrated by the caretakers with higher education level $(p<0.001)$ and higher family income $(p=0.01)$, and of higher social class $(\mathrm{p}=0.01)$.

Conclusions: The overall knowledge and practices on burn prevention were satisfactory among principal caretakers of children under five years. However, the study identified certain instances the caretakers had failed to apply their knowledge in safety practices.
\end{abstract}

Key words: burns, unintentional injuries, burn prevention 


\section{Introduction}

Curiosity and exploring objects around them is a natural phenomenon of children's development. This way, they will acquire their survival skills (1). However, this behaviour can lead to a potentially lethal hazard if the households are not safe for children. Evidence from a multi-national study revealed that out of all the accidental injuries observed, 13\% were due to burns, and out of all the burn victims, 52\% were children younger than five years of age (2). In 2012, a study carried out in a semiurban setting in Sri Lanka disclosed that out of all types of accidental injuries among toddlers, 6.9\% were caused by burns and scalds (3).

In a global perspective, more than 95\% of all reported fire-related burns occur in low- and middleincome countries (1). Similarly, within a country, burns are predominant among people with low socio-economic status. A Sri Lankan study revealed that more than twothird of children presenting with burns to Lady Ridgeway Hospital (LRH) had been from lower socio-economic families (4). The most common setting for burns was the domestic environment, within which most were encountered in the kitchen $(3,4)$. Identification of the place of injuries as 'home' provides the opportunity to plan more focused interventions to prevent these injuries, which remains to be the single best management strategy.

The causes of childhood unintentional burns are not random, but predictable; therefore, preventable. However, parental perception related to the preventability of childhood injuries has been a mixed one. According to some studies, parents are well aware that burn injuries are preventable, while it is not so with the others $(5,6)$. Parental education level, employment and monthly income of the family are some of the key factors associated with their knowledge on injury prevention and childhood burns $(7,8)$. Accordingly, raising public awareness on burns and community-based action has been identified as some of the most effective interventions for burn prevention (9).

In Sri Lanka, only a limited number of studies have been carried out to evaluate the knowledge on prevention of unintentional burns. Even among those studies, the majority had been hospital-based and therefore, the information at the community level is scarce. Similar studies carried out in other countries have disclosed that the overall parental knowledge was satisfactory but certain aspects of knowledge and many aspects of unsafe practices required further improvement $(6,8)$.
To prevent accidental burns among young children, the principal caretakers should be mindful of the potential risks at home. Children explore their environment; thus, it is crucial to look at the current status from their perspective to make sure the home is safe. The objective of this study was to describe the knowledge, practices and associated factors on childhood unintentional burn prevention among principal caretakers of children under five years in a semi-urban area.

\section{Methods}

This community-based cross-sectional study was carried out between August 2015 and January 2016 in Chilaw Medical Officer of Health (MOH) area belonging to the district of Puttalam in Sri Lanka. The study population consisted of principal caretakers of children aged less than five years, residing in Chilaw MOH area. Principal caretakers of children with special needs were excluded from the study. The study unit comprised a child under five years and his/ her principal caretaker as a pair. The principal caretaker was defined as mother or any other person in the household who has been looking after the child most of the time (more than 6 hours) during the day when the child was awake.

The required minimal sample size was calculated using a standard formula for descriptive studies (10). Due to scarcity of research related to caretakers' knowledge and practices on childhood burn prevention, the proportion having good knowledge and/or practices was considered as 50\%. Given an alpha error of 5\%, absolute precision of $5 \%$ on either side and a design effect of 1.2 , the sample size computed was 460 . Non-response rate was taken as $8 \%$. The calculated minimum sample size of 501 was rounded-up and finalized as 506 .

A two-stage cluster sampling method was used to select the sample using probability proportionate to size. In the first stage, 22 out of 27 Public Health Midwife (PHM) areas were randomly selected. For this selection, the sampling frame used was a list of all children under five years in each PHM area, which was updated using the Birth and Immunization registers. In the second stage, 23 study subjects were chosen as a cluster from each selected PHM area in a systematic manner. After selecting the first study subject randomly from the registers, the subsequent ones were recruited by visiting households until the total of 23 subjects was covered.

The study instrument was a pre-tested interviewer-administered questionnaire. In developing this 
instrument, face validity was assessed by a group of mothers having children younger than five years recruited from another $\mathrm{MOH}$ area. In addition, a comprehensive literature review and a series of consultative meetings with a group of experts (including a paediatrician, consultant community physicians, LRH burns unit medical officers and nursing officers) were completed to assess the content validity. Three medical graduates participated in data collection following several sessions of training that were conducted to train them. The questionnaire consisted of 41 items to assess each caretaker's knowledge (20 questions) and practices (21 questions) on burn prevention. For each item, there were three responses ('Yes', 'No', and 'Don't know'). For each item, a score was given for each correct response $(+1)$, answer not known (0) and for each incorrect response (0). Cumulative scores were calculated separately for good knowledge and for safe practices. The factors checked for associations with the overall knowledge and practices among caretakers were level of education, the state of employment, monthly family income, the relationship of the principal caretaker to the indexed child and social class.

Statistical analyses were conducted employing Statistical Package for Social Sciences (SPSS) software version 16. Knowledge and practices were described using frequencies and percentages. Multiple linear regression analyses were performed to calculate standardized coefficients to recognize the significant socio-demographic and economic factors associated with the scores obtained for knowledge and practices. Categorical variables were dichotomized based on their demographic importance during analysis. $P$ value less than 0.05 was considered as statistically significant. Multiple linear regression analyses were adopted in this study to control the effects of known confounders.

\section{Results}

In 18 out of 506 households, the family members were not available during the initial and subsequent home visits. Out of the remaining 488 households, the principal caretakers of 462 households responded to the questionnaire, giving a response rate of $91.3 \%$. The median age of principal caretakers was 27 years with Inter-Quartile Range (IQR) of 24-31 years. Most of the principal caretakers were females, accounting for $97.6 \%$ $(n=451)$ of the respondents. Results revealed that 418 (90.5\%) principal caretakers were the mothers of index children (Table 1). Others included in the sample were 6
(1.3\%) domestic helpers and 12 (2.6\%) teenagers. Fourteen were over 60 years of age. Over $70 \%$ of mothers had either passed GCE Ordinary Level (O/Level) or achieved a higher level of education. In terms of employment, a majority of them were unemployed. The median monthly income was Rs. 35,000 while IQR was Rs. 25,000-50,000. In most of the families, the selfreported monthly income was below Rs. 45,000.

In $60.3 \%$ of the families ( $\mathrm{n}=279$ ), there were only two children whereas in another $5 \%(n=23)$, there were four or more children. In most of the occasions, birth order of the selected child was first $(\mathrm{n}=253,54.8 \%)$. Second and third birth orders were $(\mathrm{n}=179,38.7 \%)$ and $(\mathrm{n}=12,3.9 \%)$, respectively. Mean age of the index child was 28.6 months ( $\mathrm{SD}=13.6)$. Based on the results, 21 burn injuries had occurred during the last 6 months, which resulted in 9 scalds, 6 flame burns, 3 contact burns, 2 electrical burns and 1 chemical burn.

Scores obtained by the caretakers of under 5 year old children on knowledge on childhood burn prevention ranged from $30.0 \%$ to $100.0 \%$, with a mean score of $75.8 \%$ (SD=11.2\%). Corresponding scores obtained for practices ranged between $23.8 \%$ and $90.4 \%$, with a mean score of $67.6 \%$ (SD=12.8\%). Twenty items were used to assess each principal caretaker's knowledge on selected aspects of burn prevention (Table 2). The majority of respondents believed that children are vulnerable to burns (75.1\%), and that caretakers can prevent childhood burns (63.2\%). Most of the participants $(72.1 \%)$ knew that many burns can be prevented by keeping the children away from the kitchen. However, over two-third of caretakers did not know the correct way of checking the temperature of child's bathing water. Twenty one items were used to determine each caretaker's practices related to prevention of burns at home settings (Table 3). Over $60 \%$ of homes did not have any safety measures to prevent children visiting the kitchen. The correlation between good knowledge score and safe practice score was evaluated and it revealed a moderate positive correlation $(\mathrm{r}=0.59, \mathrm{p}<0.001)$.

Multiple linear regression analyses were used to determine the socio-demographic characteristics influencing the caretaker's knowledge and practices on unintentional burn prevention. Those who had been educated up to $\mathrm{O} /$ Level or above showed significantly better knowledge scores $(\mathrm{p}<0.001)$, as well as good practice scores $(p<0.001)$ than those who were educated below O/Level. Similarly, families with a higher family 
income showed significantly better knowledge $(\mathrm{p}=0.04)$ and practices ( $\mathrm{p}=0.01$ ) than families with a lower income. When mother was the principal caretaker, knowledge on burn prevention was significantly higher $(p=0.002)$ compared to non-mother caretakers (Table 4). Social class was identified as a factor significantly associated with caretakers' practices $(\mathrm{p}=0.01)$. The caretakers belonging to higher social class demonstrated significantly better safety practices than those who were in lower social class (Table 5).

\section{Table 1. Distribution of the principal caretakers by their socio-demographic characteristics}

Socio-demographic characteristics $(\mathrm{N}=462) \quad$ No $\quad(\%)$

Age (years completed at the last birthday)

$<20$

$12 \quad 2.6$

$20-39$

426

$40-59$

\section{Highest level of education}

$\begin{array}{lrr}\text { No schooling } & 1 & 0.2 \\ \text { Grade } 1 \text { - } 5 & 22 & 4.8 \\ \text { Grade 6 - 11 } & 111 & 24.0 \\ \text { Passed O/Level examination } & 169 & 36.6 \\ \text { Passed A/Level examination } & 138 & 29.9 \\ \text { Higher education / University education } & 21 & 4.5\end{array}$

\section{Current employment status}

$\begin{array}{lll}\text { Employed } & 99 & 21.4\end{array}$

$\begin{array}{lrr}\text { Unemployed } & 363 & 78.6\end{array}$

\section{Social Class ${ }^{1}$}

Class 1 Leading professions and business

Class 2 Lesser professions and business

Class 3 Skilled workers, Non- manual workers

\} Lower social class $\quad 135 \quad 29.2$

Class 4 Partially skilled workers

Class 5 Unskilled workers

Lower social class

22

\section{Monthly family income (Rs.)}

$<15,000$

$11 \quad 2.4$

$15,000-30,000$

\footnotetext{
${ }^{1}$ Social class was categorized based on father's occupation; if the father has passed away/ separated, it was categorized based on mother's occupation; social classes 1,2 and 3 amalgamated as 'higher' social class, and 4 and 5 as 'lower' social class (Source: Social class based on occupation, Registrar General of England 1991).
} 
Table 2. Distribution of the principal caretakers by knowledge on selected aspects of burn prevention

\begin{tabular}{|c|c|c|c|c|c|}
\hline & \multirow[t]{2}{*}{ Knowledge on burn prevention $(\mathrm{N}=462)$} & \multicolumn{2}{|c|}{ Yes $^{1}$} & \multicolumn{2}{|c|}{$\mathbf{N o}^{2}$} \\
\hline & & No. & $\%$ & No. & $\%$ \\
\hline 1 & Children are more vulnerable to accidental burns & 347 & 75.1 & 115 & 24.9 \\
\hline 2 & Children can get attracted to some characteristics of fire & 270 & 58.4 & 192 & 41.6 \\
\hline 3 & $\begin{array}{l}\text { During a home fire children are more likely to hide inside the home } \\
\text { than running away from the danger }\end{array}$ & 267 & 57.8 & 195 & 42.2 \\
\hline 4 & Accidental burns can be prevented & 292 & 63.2 & 170 & 36.8 \\
\hline 5 & Many burns can be minimized by preventing children coming to the kitchen & 333 & 72.1 & 129 & 27.9 \\
\hline 6 & Not to walk with a hot liquid in the kitchen without ensuring kids are not around & 345 & 74.7 & 117 & 25.3 \\
\hline 7 & It is not safe to drink hot beverages with while carrying a baby & 310 & 67.1 & 152 & 32.9 \\
\hline 8 & Correct way of checking the temperature of child's bath water & 105 & 22.7 & 357 & 77.3 \\
\hline 9 & Smoking inside home increases the fire risk at household & 386 & 83.5 & 76 & 16.5 \\
\hline 10 & Inhalation of smoke could cause burns inside child's respiratory tract & 283 & 61.3 & 179 & 38.7 \\
\hline 11 & They should always store highly inflammable substances in a safe protected place & 290 & 62.8 & 172 & 37.2 \\
\hline 12 & It is not safe to allow kids to play with fireworks & 417 & 90.3 & 45 & 9.7 \\
\hline 13 & $\begin{array}{l}\text { The importance of teaching their children that iron, kettles, and heaters can have } \\
\text { hot surfaces sometime after use. }\end{array}$ & 291 & 63.0 & 171 & 37.0 \\
\hline 14 & $\begin{array}{l}\text { The importance of teaching their kids that cooking pots, and cookers can be } \\
\text { very hot soon after cooking }\end{array}$ & 276 & 59.7 & 186 & 40.3 \\
\hline 15 & Importance of teaching their kids that some parts of vehicles (e.g. motorbikes) & & & & \\
\hline & can be very hot and can cause a burn if they touch it while the engine is on & 233 & 50.4 & 229 & 49.6 \\
\hline 16 & Children can get burned by touching the electric bulbs & 298 & 64.5 & 164 & 35.5 \\
\hline 17 & Electrical outlets need to be covered or place them inaccessible for children & 287 & 62.1 & 175 & 37.9 \\
\hline 18 & $\begin{array}{l}\text { Importance of placing electrical equipment (like televisions, computers, and } \\
\text { stereo equipment) against walls to prevent electricity burns }\end{array}$ & 236 & 51.1 & 226 & 48.9 \\
\hline 19 & Can prevent electrocution by placing a rubber floor carpet in front of the fridge & 264 & 57.1 & 198 & 42.9 \\
\hline 20 & Importance of proper grounding of all major electrical appliances & 291 & 63.0 & 171 & 37.0 \\
\hline
\end{tabular}

${ }^{1}$ Correct response for each item was categorized under "Yes" response

${ }^{2}$ Both incorrect response and don’t know response were categorized under “No” response 
Table 3. Distribution of the principal caretakers by practices related to selected aspects of burn prevention

\begin{tabular}{|c|c|c|c|c|c|}
\hline \multicolumn{2}{|r|}{ Practices on burn injury prevention $\quad(\mathrm{N}=462)$} & \multicolumn{2}{|c|}{ Yes $^{1}$} & \multicolumn{2}{|c|}{$\mathrm{No}^{2}$} \\
\hline & & No. & $\%$ & No. & $\%$ \\
\hline 1 & Checked for potential risks (hazards) for fire around your home & 288 & 62.3 & 174 & 37.6 \\
\hline 2 & Discussed on what they should do in case of a fire at your home & 158 & 34.2 & 304 & 65.8 \\
\hline 3 & Had any arrangements like safety measures to prevent burns & 249 & 53.9 & 213 & 46.1 \\
\hline 4 & Always make sure that child is under close supervision & 309 & 66.9 & 153 & 33.1 \\
\hline 5 & Taken safety measures to prevent child coming to the kitchen & 181 & 39.2 & 281 & 60.8 \\
\hline 6 & Always checks the temperature of hot food items before start feeding & 316 & 68.4 & 146 & 31.6 \\
\hline 7 & Never cook by holding a baby or keeping a small child around & 285 & 61.7 & 177 & 38.3 \\
\hline 8 & $\begin{array}{l}\text { As a practice does not keep hot drinks or curry pots on tablecloths } \\
\text { extend beyond from tables margins }\end{array}$ & 322 & 69.7 & 140 & 30.3 \\
\hline 9 & No one smokes inside the home or around the household & 405 & 87.6 & 57 & 12.2 \\
\hline 10 & $\begin{array}{l}\text { Keeps/store any of these items (matches, lighters, candles and fireworks) } \\
\text { in a place inaccessible to children }\end{array}$ & 266 & 57.6 & 196 & 42.4 \\
\hline 11 & Not using any kind of an unsafe kerosene/ coconut oil lamps at home & 393 & 85.1 & 69 & 14.9 \\
\hline 12 & $\begin{array}{l}\text { Always pour water and put out the fire before you leave the place of } \\
\text { burning garbage/ tree leaves }\end{array}$ & 117 & 25.3 & 345 & 74.7 \\
\hline 13 & $\begin{array}{l}\text { Always read consumer instructions before applying any form of an application } \\
\text { on their child's skin }\end{array}$ & 185 & 40.0 & 277 & 60.0 \\
\hline 14 & Ensure to turn off the cooker, wood or Kerosene oil-burning stove after cooking & 381 & 82.5 & 81 & 17.5 \\
\hline 15 & $\begin{array}{l}\text { Never apply any form of an application on child's skin without knowing their } \\
\text { possible side effects }\end{array}$ & 241 & 52.1 & 221 & 47.8 \\
\hline 16 & Never store chemicals in any other containers attractive to children & 387 & 83.8 & 75 & 16.3 \\
\hline 17 & $\begin{array}{l}\text { Always store chemicals (cleaning products, acids, and corrosives) } \\
\text { in a place inaccessible for children }\end{array}$ & 210 & 45.5 & 252 & 54.5 \\
\hline 18 & Not allow children to use electrical appliances without an adult supervision & 342 & 74.0 & 120 & 26.0 \\
\hline 19 & Unplug all non-using electrical appliances & 189 & 40.9 & 273 & 59.1 \\
\hline 20 & Checked whether the trip switch is functioning normally (During past 12 months) & 104 & 22.5 & 358 & 77.5 \\
\hline 21 & Do not use any electrical appliances that are in poor condition. & 256 & 55.4 & 206 & 44.6 \\
\hline
\end{tabular}

${ }^{1}$ Correct response for each item was categorized under "Yes" response

${ }^{2}$ Both incorrect response and don't know response were categorized under “No” response 
Table 4. Multiple linear regression to determine the socio-demographic characteristics influencing the knowledge of principal caretakers on unintentional burn prevention

\begin{tabular}{|c|c|c|c|c|c|}
\hline \multirow[t]{3}{*}{ Characteristics of the principal caretaker } & \multirow[b]{3}{*}{$\beta$} & \multicolumn{2}{|c|}{ 95\% Confidence Interva } & \multirow[b]{3}{*}{ t-value } & \multirow[b]{3}{*}{$\begin{array}{l}\text { Sig. } \\
\text { (p value) }\end{array}$} \\
\hline & & Lower & Upper & & \\
\hline & & & & & \\
\hline Relationship to index child (Non-mother) & 1.52 & 0.57 & 2.47 & 3.13 & $0.002^{*}$ \\
\hline Age (Lower age) & 0.03 & -0.001 & 0.06 & 1.79 & 0.06 \\
\hline Level of education (Grade 11 or below) & 1.23 & 0.72 & 1.73 & 4.83 & $<0.001^{*}$ \\
\hline Employment status (Employed) & 0.07 & -0.49 & 0.63 & 0.25 & 0.8 \\
\hline Monthly family Income (Lower income) & 1.24 & 0.73 & 1.74 & 3.58 & $0.04^{*}$ \\
\hline Social class (Low Social class) & 0.37 & -0.11 & 0.85 & 1.52 & 0.13 \\
\hline
\end{tabular}

*Statistical significance $(\mathrm{p}<0.05)$

Dependent variable: overall Knowledge related to burns prevention

Reference for independent variables is given within ( ) for each variable

Table 5. Multiple linear regression to determine the socio-demographic characteristics influencing the practices of principal caretakers on unintentional burn prevention

\begin{tabular}{|c|c|c|c|c|c|}
\hline \multirow[t]{3}{*}{ Characteristics of the principal caretaker } & \multirow[b]{3}{*}{$\beta$} & \multicolumn{2}{|c|}{ 95\% Confidence Interva } & \multirow[b]{3}{*}{ t-value } & \multirow[b]{3}{*}{$\begin{array}{l}\text { Sig. } \\
\text { (p value) }\end{array}$} \\
\hline & & \multirow[t]{2}{*}{ Lower } & \multirow[t]{2}{*}{ Upper } & & \\
\hline & & & & & \\
\hline Relationship to index child (Non-mother) & 0.3 & -0.8 & 1.41 & 0.53 & 0.59 \\
\hline Age (Lower age) & 0.02 & 0.02 & 0.06 & 1.14 & 0.26 \\
\hline Level of education (Grade 11 or below) & 1.4 & 0.82 & 1.99 & 4.69 & $<\mathbf{0 . 0 0 1}^{*}$ \\
\hline Employment status (Employed) & 0.24 & -0.41 & 0.89 & 0.73 & 0.46 \\
\hline Monthly family Income (Lower income) & 1.92 & 1.13 & 2.7 & 2.77 & $0.006^{*}$ \\
\hline Social class (Low Social class) & 0.73 & 0.17 & 1.29 & 2.55 & $\mathbf{0 . 0 1 1}^{*}$ \\
\hline
\end{tabular}

${ }^{*}$ Statistical significance $(\mathrm{p}<0.05)$

Dependent variable: overall Knowledge related to burns prevention

Reference for independent variables is given within ( ) for each variable

\section{Discussion}

The mean score obtained by caretakers of children below five years of age for their knowledge on childhood burn prevention was $75.8 \%(\mathrm{SD}=11.2 \%)$. The corresponding mean score obtained for their practices was $67.6 \%(\mathrm{SD}=12.8 \%)$. However, certain aspects of practices were deemed poor, creating a gap between the knowledge and actual safe practices. Some of the socio- demographic characteristics were found to be significantly associated with caretakers' knowledge as well as practices.

Our study revealed that $75 \%$ of participants knew that children are more vulnerable to burns. In addition, $63.2 \%$ of the principal caretakers were aware of the fact that accidental burns are preventable. Findings of a 
Canadian community-based study that assessed the maternal perception on preventability of burns and toddlers' vulnerability to burns were similar to our study (6). Higher literacy rate and maternal education level among Sri Lankan caretakers were compatible with Canadian caretakers, which could have attributed to this higher level of knowledge.

The World Health Organization states fireworks as one of the riskiest consumer products available, and highlights the importance of public awareness on its dangers and setting legislations to limit its usage (11). According to our findings, over $90 \%$ of the caretakers knew it was not safe to allow children to play with fireworks. A possible reason for having such good knowledge could be a result of effective public health programs that raise risk awareness regarding fireworks. However, this study identified that only 57.6\% households had stored fire hazardous items (matches, lighters, and fireworks) in places that are inaccessible for children. It is a proven fact that children playing with matches and lighters frequently set houses on fire including fatal childhood burns (12). Public awareness programs should address these issues in health messages by emphasizing on the importance of safe storage of the hazardous items.

According to the findings of this study, $72.1 \%$ of the principal caretakers knew that many childhood burns could be prevented by stopping children coming to the kitchen. However, only 39.2\% households had safety measures in place to stop children from this act, suggesting a gap between the knowledge and practices. A Sri Lankan hospital-based cross-sectional study revealed a seasonal pattern for burns in kitchens, where burns were commonly seen during April and December months (13). The reason behind may be due to underestimating the potential hazards at home owing to children being neglected during festive seasons. Community-based health promotion programs can address this need by encouraging caretakers to set safety-barriers to stop children coming to cooking areas. Furthermore, mass media can be used especially during festival seasons to raise parental awareness to pay more attention to their children's behaviour.

The proportion of homes in which caretakers stored chemicals (e.g. cleaning products, acids, and corrosives) in places inaccessible for children was below 50\%. In contrast, a study from Saudi Arabia revealed that in up to
$74 \%$ of the families, parents kept detergents and other chemicals in secured cabinets inaccessible to children (14). Such difference between the two studies could be due to the availability of separate storage facilities in modern homes in high income countries in contrast to that in a suburban home in Sri Lanka. In Sri Lanka, public health inspectors (PHIs) can advise the clients with new building applications to have a separate storage space for chemicals. Similarly, PHIs and PHMs can allocate time during their home visits to inspect each home surroundings and encourage the caretakers to implement safety measures.

This study uncovered that only $40 \%$ of the participants always unplugged all electrical appliances when they were not in use. In contrast, a communitybased study carried out in Kolonnawa $\mathrm{MOH}$ area reported that during home visits, $82.3 \%$ houses kept unused electrical appliances unplugged (3). The reason for caretakers in Kolonnawa $\mathrm{MOH}$ area to have better electrical safety practices compared to the participants from Chilaw $\mathrm{MOH}$ area could be due to inter-district urban-rural disparities in enforcing safety practices.

A previous study that assessed factors associated with injuries among children aged 1-4 years in Kolonnawa $\mathrm{MOH}$ area reported a significantly lower level of unintentional injuries among children cared by mothers during day time (3). This is in concurrence with our study findings, where higher mean scores of knowledge and practices were seen among mothers compared to other caretakers. This could be a result of significantly higher knowledge on burn prevention among mothers. Therefore, to protect children from burns, it is equally important to improve the knowledge of others who would be looking after the children.

Several studies carried out in other low- and middleincome countries (in Bangladesh and Turkey) have identified significantly higher knowledge and practices on burn prevention associated with a higher education level among the caretakers $(7,15)$. Findings of these studies are consistent with the present study, where significantly higher knowledge and safe practices were evident among the caretakers who were educated up to $\mathrm{O} /$ Level and above. With better education, the caretakers become more knowledgeable about how to protect their children from unintentional burns. On the other hand, higher education enables parents to recognize the importance of safety measures, close supervision and limiting their exposure to hazards. 
Studies carried out in both Sri Lanka and Western countries have identified higher family income as a significant association for both increased knowledge and good practices $(4,7)$. Our study results are similar to these findings. A higher income leads to purchasing of higher quality and safer material such as standard electrical appliances, safety plugs and trip switches, which would eventually protect their children.

In our study, caretakers belonging to a higher social class demonstrated significantly better safety practices than those belonging to a lower social class. Our study defined 'social class' based on father's occupation, since Sri Lankan households are male dominated; and therefore, fathers seem to play an important role in homeenvironment modification. This further suggests that fathers' occupation may have an influence on home safety practices. Therefore, fathers should also be targeted when conducting health education on home safety practices.

This study sample was limited to one $\mathrm{MOH}$ area; thus, the findings may not be generalized to a wider population. Our study may not represent all the aspects of childhood burns. Factors such as presence of other siblings, past history of burns in index or other siblings could act as confounders for knowledge and practices of caretakers, which was not assessed in this study. There also could have been some unequally distributed unknown confounders affecting the true associations. During the data collection, there could have been a degree of recall bias. Regardless of these limitations, this study makes an important contribution to the childhood injury prevention literature.

\section{Conclusions and Recommendations}

This study revealed that the majority of caretakers had good knowledge as well as practice scores related to childhood burn prevention. Some socio-demographic characteristics were significantly associated with caretaker's knowledge and practices. However, the caretakers failed to apply their knowledge to enhance safety in certain aspects such as modification of the kitchen environment and storage of chemicals and inflammable items. These gaps between knowledge and practices are recommended to be addressed through more focussed interventions on environmental modification, legislation and by health promotion to improve social determinants.

\section{Public health implications}

Better knowledge on childhood burn prevention does not ensure a safe environment for children even by adopting simple measures such as making the kitchen less accessible and safe storage of chemicals and inflammables. Emphasis should be on interventions transforming knowledge into sustainable behavioural change among child caretakers. More attention should be on families with children in low socio-economic environments.

\section{Author Declarations}

Competing interests: The authors declare that they have no competing interests.

Ethics approval and consent to participate: Ethics clearance was obtained from the Ethics Review Committee of the Postgraduate Institute of Medicine (ERC/PGIM/004/2015/51 on 27/07/2015), Sri Lanka. Administrative clearance to collect data was obtained from the Regional Director of Health Services Puttalam and $\mathrm{MOH}$ Chilaw areas. Informed written consent was obtained from each study participant. Personal identification data were not included in the questionnaire.

\section{Funding: None.}

Acknowledgements: We would like to express our gratitude to Chilaw $\mathrm{MOH}$, her staff and study participants.

Author contributions: DW was the principal investigator of the study. DW \& RB were involved in the concept, design and interpretation of data. DW was involved in data collection and drafting the manuscript. DW \& RB revised it critically for important intellectual content and gave final approval.

\section{References}

1. WHO.World report on child injury prevention. Geneva: World Health Organization, 2008.

2. Hyder AA, Sugerman DE, Puvanachandra P, Razzak J, El-Sayed H, Isaza A, Rahman F, Pedenet M. Global childhood unintentional injury surveillance in four cities in developing countries: a pilot study. Bulletin of the World Health Organization 2009; 87(5): 345-352.

3. Punyadasa DH. Incidence and associated family related 
factors of unintentional injuries among 1-4 year old children in the Medical Officer of Health area Kolonnawa. Colombo: Post Graduate Institute of Medicine, University of Colombo, 2012.

4. Ariyaratne KA. Characteristics of patients with burn injuries admitted to Lady Ridgeway Hospital for Children. Colombo: Post Graduate Institute of Medicine, University of Colombo, 1995.

5. Morrongiello BA \& Dayler L. A community-based study of parents' knowledge, attitudes and beliefs related to childhood injuries. Canadian Journal of Public Health 1996; 87(6): 383-388.

6. Morrongiello BA, Kiriakou S. Mothers' home-safety practices for preventing six types of childhood injuries: what do they do and why? Journal of Paediatric Psychology 2003; 29(4): 285-297.

7. Daisy S, Mostaque AK, Bari TS, et al. Socio-economic and cultural influence in the causation of burns in the urban children of Bangladesh. Journal of Burn Care \& Rehabilitation. 2001; 22(4): 269-273.

8. Hatamabadi HR, Mahfoozpour S, Alimohammadi H, Younesian S. Evaluation of factors influencing knowledge and attitudes of mothers with preschool children regarding their adoption of preventive measures for home injuries referred to academic emergency centres Tehran Iran.
International Journal of Injury Control and Safety Promotion 2014; 21(3): 252-259.

9. WHO. Child and adolescent injury prevention: a global call to action. Geneva: World Health Organization, 2005.

10. Lwanga SK, Lemeshow S. Sample size determination in health studies: a practicle manual. Geneva: World Health Organization, 1991.

11. WHO. Burns prevention: success stories from lessons learned. Geneva: World Health Organization, 2011.

12. Warda L, Tenenbein M, Moffatt M. House fire injury prevention update. Part I. A review of risk factors for fatal and non-fatal house fire injury. Injury Prevention 1999; 5(2): 145-150.

13. Ariyaratne KA. Characteristics of patients with burn injuries admitted to Lady Ridgeway Hospital for children. Colombo: Post Graduate Institute of Medicine, University of Colombo.

14. Jan MM, Hasanain FH, Al-Dabbagh AA. Infant and child safety practices of parents. Saudi Medical Journal 2000; 21(12): 1142-1146.

15. Atak N, Karaoðlu L, Korkmaz Y, Usubütün S. A household survey: unintentional injury frequency and related factors among children under five years in Malatya. Turkish Journal of Pediatrics 2010; 52(3): 285-293. 